\title{
A Revista do Ginásio Londrinense e as linhas da história: títulos, textos e imagens que evocam uma época, sob a ótica dos ginasianos pioneiros de Londrina
}

\section{Revista do Ginásio Londrinense and the lines of history: titles, texts and images that recreate a time in the perspective of Londrina's first students}

\author{
Juliana de Oliveira Teixeira ${ }^{1}$; Paulo César Boni²
}

\begin{abstract}
Resumo
A Revista do Ginásio Londrinense, meio de comunicação e expressão dos estudantes do Ginásio Londrinense, nasceu e circulou em meados da década de 40, em meio a um ambiente conturbado pela Segunda Guerra Mundial e pela ditadura de Getúlio Vargas. Produzida pelos alunos, a revista representa não só uma forma de expressão, mas o retrato de toda uma época. Para a produção deste artigo, além da metodologia de revisão de literatura, foram adotadas técnicas de análise e de história oral, com a realização de entrevistas pessoais. Em termos gerais, ficou explícita a importância de veículos impressos, independente de seu tamanho ou periodicidade, para o resgate e preservação da história.
\end{abstract}

Palavras-chave: História de Londrina (PR). História oral. Revista do Ginásio Londrinense. GLERB.

\begin{abstract}
Revista do Ginásio Londrinense, a means of communication and expression of Ginásio Londrinense's students, was created and circulated around the 1940's, in an environment troubled by the Second World War and by Getúlio Vargas's dictatorship. Made by the students, the magazine not only represented a way of expression, but also the reflection of an entire era. For the production of this article, besides literature review, other techniques of analysis and oral history were utilized, with personal interviews. In general terms, the importance of printed means of communication was explicit, independent of its size or periodicity, for the recuperation e preservation of history.
\end{abstract}

Keywords: History of Londrina (PR). Oral history. Revista do Ginásio Londrinense. GLERB.

\footnotetext{
1 Estudante de Comunicação Social - Habilitação Jornalismo da Universidade Estadual de Londrina. Bolsista de Iniciação Científica do projeto de pesquisa A História de Londrina (década de 40) em textos e imagens, em desenvolvimento na Universidade Estadual de Londrina. Endereço: Rua Jerusalém, 180, apto 401. Londrina - Paraná. Telefone: (43) 3304-3059. E-mail: juoliveira. teixeira@gmail.com. Categoria de Trabalho: Sociais/Humanas; Sub-Área CNPq/CAPES: Comunicação.

2 Orientador do projeto de Iniciação Científica. Professor Doutor e pesquisador da Universidade Estadual de Londrina. Endereço: Avenida Garibaldi Deliberador, 231 - Apto. 172 - Jardim Cláudia - Londrina - Paraná. Telefone: (43) 3371-4328. E-mail: pcboni@sercomtel.com.br.
} 


\section{Introdução}

Este artigo apresenta e analisa a Revista do Ginásio Londrinense, meio de comunicação dos alunos do grêmio estudantil do Ginásio Londrinense - instituição de ensino fundada na década de 40. Para tanto, extrapola a situação da educação e traça um panorama do que era a cidade na época e das influências que ela sofria da Segunda Guerra Mundial e da ditadura de Getúlio Vargas. Dessa forma, busca-se ter uma visão mais ampla da realidade dos primeiros ginasianos de Londrina. $\mathrm{O}$ artigo tem como objetivo identificar em que medida esse ambiente e preocupações da época se manifestaram nas linhas da revista. A busca por resposta foi fundamentada, sobretudo, na concepção de Borges (2001, p. 62-64), que considera os meios de comunicação "fontes riquíssimas para a história dos tempos mais próximos [...]. Por meio da multiplicidade de informações [...] que nos chegam em um jornal, podemos atingir muito da riqueza da realidade multifacetada de outros tempos e outros espaços".

Para o desenvolvimento deste trabalho, foram utilizados referenciais teóricos acerca da história de Londrina, como livros, teses, revistas, boletins e arquivos de pioneiros. Para sanar as dúvidas que surgiram, devidas principalmente, à escassez de informações e documentos de época, foi utilizada a técnica de história oral. Segundo, Thompson (2002, p. 44), a história oral pode ser muito importante, à medida que constrói o passado em torno de pessoas, "lança a vida para dentro da própria história". Mais do que fornecer novos dados à pesquisa, a história oral "pode devolver às pessoas que fizeram e vivenciaram a história um lugar fundamental, mediante suas próprias palavras." (THOMPSON, 2002, p. 22).

Segundo Meihy (2002, p. 15), a história oral é a "história viva", pois "possibilita uma percepção do passado como algo que tem continuidade hoje e cujo processo histórico não está acabado". Dessa forma, a técnica é capaz de propiciar "um diálogo entre as diferentes fontes escritas e orais." (BESPALHOK, 2006, p. 23).

Como a história oral se vale da memória dos entrevistados, pode-se argumentar que eles não são suficientemente objetivos para a sistematização de acontecimentos históricos. Para tanto, Bespalhok (2006, p. 18) defende que, "de uma forma ou de outra, as fontes históricas, sejam as orais, escritas ou visuais, têm traços de subjetividade [...]". Por isso, assim como em outras formas de recuperação do passado, é preciso ter uma preocupação crítica em relação à fonte oral. Thompson (2002, p. 138) menciona algumas atitudes fundamentais para a correta utilização dessa técnica: "buscar a consciência interna, procurar confirmação em outras fontes e estar alerta quanto ao viés potencial".

\section{Antes de "Capital Mundial do Café", a "Boca do Sertão"}

Londrina, norte do Paraná, está a 400 quilômetros da capital do estado, Curitiba. Com 497.833(IBGE, 2008) habitantes, é uma das maiores cidades da Região Sul - e, também, uma das mais recentes, com apenas 74 anos de emancipação política. De 1934 até 2008, teve um crescimento rápido e contínuo, passando de "boca do sertão", nos anos 30, a "capital mundial do café", nos anos 60. Esse crescimento é fruto do avanço da colonização e da intensificação da entrada de imigrantes estrangeiros, como alemães, holandeses, italianos, espanhóis, portugueses e japoneses.

Os ingleses, mais pelos empreendimentos que pelo número de imigrantes, tiveram forte participação na colonização norte paranaense. A fertilidade do solo os interessou - e muito - tanto que, em 1925, no dia 24 de setembro, foi fundada em São Paulo a Companhia de Terras Norte do Paraná (CTNP). Com o capital essencialmente inglês, 99,86\%, e com sócios brasileiros, "a CTNP comprou 515.000 alqueires paulistas de terras 
(cada alqueire paulista corresponde a $24.200 \mathrm{~m}^{2}$ ) para dar início ao seu projeto de colonização." (BONI, 2004, p. 32).

Foi assim que, a partir de 1929, Londrina deu os primeiros passos. Atraídos pela possibilidade de ter a própria terra, brasileiros e imigrantes das mais diversas nacionalidades vieram colonizar a região. Em 1934, tornou-se município ${ }^{3}$ por força do Decreto $\mathrm{n}^{\circ}$ 2.519, assinado em 3 de dezembro, pelo interventor do estado do Paraná, Manoel Ribas (BONI, 2004, p. 104). Como município, Londrina teve que ampliar e aprimorar sua organização, principalmente com relação à infra-estrutura que, até então, era de inteira responsabilidade da CTNP. Energia elétrica, abastecimento de água, saneamento, assistência médica, calçamento de ruas, transporte, educação - todos esses serviços tinham que acompanhar o crescimento populacional. Essas expectativas e necessidades foram favoráveis à criação do Ginásio Londrinense, em particular, e à educação - nosso objeto de Iniciação Científica - como um todo.

\section{A Educação em Londrina}

A educação de Londrina teve um começo difícil e fragmentado, pontuado, principalmente, pela iniciativa particular. Com a vinda de muitos imigrantes, o número de diferentes etnias era grande e, consequentemente, o de idiomas também. Boni (2004, p. 187) explica que, povos de origem latina como os italianos e espanhóis, ainda tinham certa facilidade para se comunicar com os brasileiros, mas, para alemães, japoneses, russos, a língua se erguia como uma verdadeira barreira à comunicação. Por isso, esses povos compravam lotes próximos, formavam grupos e acabavam criando um "pedaço" de sua terra natal "falando sua língua [...], vestindo suas roupas, comemorando suas festas típicas, praticando a sua religião, preservando sua cultura, gastronomia, hábitos e costumes" (BONI, 2004, p. 187).

Dessa forma, nada mais natural que os estrangeiros também criassem suas próprias escolas - ação essa reforçada por uma "formação cultural diferenciada, não aceitando a hipótese de seus filhos ficarem sem escola" (CESAR, 1976, p. 35). E eles não só criaram, como foram os pioneiros da educação em Londrina, com a Escola Alemã de Heimtal$^{4}$, em 1931, e a Escola Japonesa, em 1933.

A primeira escola em língua portuguesa, a "escolinha” só foi instalada em 1934, num pequeno salão cedido pela CTNP. Só havia uma sala de aula e as crianças eram divididas em turmas matutinas, vespertinas e noturnas. O número de alunos é incerto, porque não há qualquer tipo de documento que traga essa informação (BONI, 2004, p. 196).

Em 1936, o Instituto Mãe de Deus ${ }^{5}$ também abriu as suas portas com 103 alunos matriculados, o que ajudou, mas não solucionou o problema de falta de vagas, visto que, segundo o Serviço de Estatística da Prefeitura de Londrina de 1937, o número de crianças da região urbana com idade escolar, ou seja, 12 anos, era de 3.606. O autor comenta:

Diante desse cenário, o problema educacional - falta de escolas e professores - ganhou magnitude e se tornou um dos principais (senão o principal) assuntos nas casas e ruas da cidade. Em pouco tempo, o problema ficou insustentável e passou a ser prioridade para a administração pública (BONI, 2004, p. 198).

\footnotetext{
3 Antes de se tornar município, Londrina pertencia ao município de Jataizinho, hoje parte da região metropolitana de Londrina.

4 Heimtal era um reduto de imigrantes alemães no início da colonização de Londrina. Hoje, a localidade mantém muitas características alemãs, principalmente na arquitetura, na religião e na gastronomia.

5 O Instituto Mãe de Deus foi criado em 3 de março de 1936 pelas Irmãs de Maria de Schoenstatt. Vindas de Vallendar, na Alemanha, as Irmãs de Maria alugaram da CTNP uma casinha de madeira no centro da recente Londrina (LAWAND, 2002, p. 31).
} 
Assim, para atender a reivindicação dos londrinenses, foi criada a primeira escola estadual na cidade, o Grupo Escolar de Londrina ${ }^{6}$. Inaugurado em 14 de julho de 1937, iniciou suas atividades com 587 matriculados, número elevado para a época, o que evidencia quanto a demanda estava reprimida. Segundo Boni (2004, p. 200), cerca de 100 alunos novos se matriculavam a cada ano.

Um fato interessante a se destacar é que, até esse momento, todos os colégios criados ofereciam somente o curso primário. $\mathrm{O}$ curso ginasial (equivalente às séries de $5^{\mathrm{a}}$ à $8^{\mathrm{a}}$, como é hoje) precisava ser feito em outras cidades - oportunidade reservada somente aos adolescentes de famílias de maior poder aquisitivo. Analisando a situação e a demanda reprimida, Jonas de Faria Castro $^{7}$ decidiu criar uma escola particular que oferecesse o ginasial - o Ginásio Londrinense.

\section{O Ginásio Londrinense}

O médico Jonas Faria de Castro, idealizador do Ginásio Londrinense, vislumbrou fundar seu estabelecimento de ensino ainda em 1939, porém "a empreitada fugia das possibilidades financeiras do Dr. Jonas à época. Ele precisou de um sócio" (BONI, 2004, p. 208). Em 1940, o médico associouse ao advogado Rui Ferraz de Carvalho e, juntos na sociedade civil Faria, Castro \& Cia. ${ }^{8}$, compraram uma quadra na região central de Londrina. Com autorização e inspeção federal, o ginásio abriu suas portas no começo de 1941, contando com os cursos Primário e de Preparação aos Exames de Admissão da turma ginasial (BOLETIM, MUSEU HISTÓRICO DE LONDRINA CARLOS WEISS, 1980, p. 31).

A primeira formatura da escola aconteceu em 1943, com uma turma de estudantes transferidos de instituições de ensino de outras cidades. Em razão dessa heterogeneidade, e por terem feito os primeiros anos em outros cursos, os primeiros formandos não são considerados os "alunos pioneiros" do Ginásio Londrinense - essa designação é reservada aos formandos de 1944, os primeiros a passarem por uma trajetória "completa" dentro da instituição.

Também foi em 1944 que chegou à Londrina, vindo de São João da Boa Vista (MG), o professor Zaqueu de Melo, ministro da Igreja Presbiteriana no Brasil dessa cidade. Convidado a lecionar português no Ginásio Londrinense, dois anos mais tarde, estaria à frente do Instituto Filadélfia, que comprou a escola da sociedade Faria, Castro \& Cia. Bertan (1990, p. 42) esclarece essa transição:

Em 1944, Zaqueu de Melo criou uma sociedade, agregando os evangélicos, com o apoio das Igrejas Protestantes de várias denominações. Inicialmente, ele recebeu o nome de Instituto Evangélico Secundário. Posteriormente, em registro oficial, a Instituição passou a denominarse Instituto Filadélfia de Londrina.

O Instituto Filadélfia organizou-se por meio de um sistema de cotas ${ }^{9}$, que podiam ser subscritas

6 Em 1941, o Grupo Escolar de Londrina teve seu nome alterado para Grupo Escolar Hugo Simas, oficializado por meio da publicação do decreto assinado pelo interventor Manoel Ribas no Diário Oficial do Estado do Paraná, em 5 de dezembro de 1941. A mudança do nome foi uma homenagem do governo estadual ao desembargador curitibano Hugo Simas, que faleceu no dia 27 de outubro de 1941.

7 Jonas de Faria Castro, médico formado pela Faculdade Nacional de Medicina do Rio de Janeiro em 1928, chegou a Londrina em 1936 e fundou a Casa de Saúde Dr. Jonas, aberta a todos os médicos da região. Contava com 16 leitos, enfermaria, cirurgia, exames clínicos. Foi ela também a sede das primeiras reuniões para a criação da Associação Médica de Londrina (PELLEGRINI, 1991, p. 23).

8 O registro da sociedade é de 21 de dezembro de 1940. Por essa razão, o Ginásio Londrinense só pôde iniciar suas obras depois dessa data.

9 De acordo com Bertan (1990, p. 43), o sistema de cotas pode ser deduzido conforme a citação do Estatuto da própria sociedade do ano de 1945: "O capital de quinhentos mil cruzeiros, divididos em cotas de quinhentos cruzeiros, o que poderá ser aumentado $[\ldots] "$. 
pelos membros de igrejas evangélicas de outras cidades. Para que se alcançasse uma meta mínima de vendas e formasse o fundo de capital necessário para o empreendimento, Zaqueu de Melo viajou durante os anos de 1944 a 1946 por diversas regiões vendendo cotas. Em 1946, com 458 subscrições e uma base sólida, a sociedade adquiriu o Ginásio Londrinense. Para tanto, conforme Bertan (1990, p. 48), preferiu não lançar mão de recursos próprios e optou por um empréstimo no valor de CR\$ 600.000,00 junto à Caixa Econômica Federal.

O recibo de compra foi emitido no dia 6 de novembro de 1946 e, a partir de 1947, a escola passou a ser administrada pelo Instituto Filadélfia de Londrina, tendo Zaqueu de Melo como presidente. Até hoje o instituto permanece à frente da escola, que expandiu-se e ganhou proporções bem maiores. Atualmente, a instituição, além de ofertar os cursos de Educação Infantil, Fundamental e Ensino Médio do Colégio Londrinense, conta com a Unifil Universidade Filadélfia de Londrina.

Neste trabalho, o recorte se apoiará nos primeiros anos do Ginásio Londrinense, principalmente na gestão Faria, Castro \& Cia., época em que foram criados o Grêmio Litero Esportivo Rui Barbosa e a sua revista mensal.

\section{GLERB - Grêmio Litero Esportivo Rui Barbosa}

Não se sabe a data precisa da fundação do Grêmio Litero Esportivo Rui Barbosa do Ginásio
Londrinense - já que a escassez de documentos é grande, inclusive no próprio colégio. Tem-se, porém, a certeza de que a sua criação foi iniciativa da turma pioneira ${ }^{10}$. Usando como fontes os números consultados da Revista do Ginásio Londrinense e as entrevistas ${ }^{11}$ com as alunas pioneiras Kilda Gomes do Prado Gimenez, Paulina de Oliveira César Silveira e Silvandira Ferrarese de Almeida, pode-se deduzir que o GLERB "nasceu junto com a turma". De acordo com o texto Perfil do Dr. Clairmont Orlando Gomes - Fundador do Grêmio Litero Esportivo Rui Barbosa, presente na Revista do Ginásio Londrinense:

1941... Estávamos em aula quando Dr. Rui Ferraz de Carvalho, acompanhado de um senhor entra em classe. Apresenta-nos a visita: - Dr. Clairmont Orlando Gomes, Professor de Educação Física. [...] Na primeira aula de educação física, propôs-nos a criação de um grêmio. Acolhemos com entusiasmo esta idéia e ali mesmo foi marcado o dia para a primeira eleição (PERFIL..., 1944, p. 5).

A figura do professor Clairmont Orlando Gomes ${ }^{12}$ foi fundamental para a formação do GLERB, já que foi o seu idealizador - e foi dele, inclusive, a sugestão do nome Rui Barbosa. Segundo as alunas pioneiras, este patrono foi escolhido devido sua importância intelectual e sabedoria. Em texto na Revista do Ginásio Londrinense edição de 1944, Rui Barbosa foi considerado "formidável palatino do Direito, da Lei, da Justiça e da Liberdade". Na ocasião da Segunda Conferência da Paz, em Haia

10 A turma pioneira do Ginásio Londrinense tem 31 alunos. São eles: Abrahão Andery, Albino Striquer, Agenor De Múzzio, Ananias Gomes Martins, Celma Azevedo, Claudimar Bueno de Menezes, Cláudio Damiano Staziak, Circe Rocha Loures Bueno, Dulce Aparecida Bonalumi, Dorothéa Passos, Esmeralda Silveira Cintra, Francisco Busto Moreno, Gumercindo Fernandes da Silva, Horácio Aizin, Haroldo de Feitas, Heronaka Tamuro, Izaurino Gomes Patriota, Iochihal Kawahisa, Jair Gomes, Kilda Gomes do Prado, Lázaro José Caria de Souza, Manoel Garcia, Maria Luiza Guimarães, Mariwo Nishioka, Milton Gensen, Octávio Venturini, Paulina de Oliveira César, Pedro Faria, Rubens de Jesus, Silvandia Ferrarese e Tupan Aguiar Borges.

11 As entrevistas foram feitas em duas etapas. A primeira apenas com a Sra. Kilda do Prado Gomes Gimenez, pessoalmente, no dia 18 de junho de 2008. E, a segunda, com três alunas pioneiras: Paulina de Oliveira César Silveira, Silvandira Ferrarese de Almeida e Kilda do Prado Gomes Gimenez, também pessoalmente, no dia 25 de junho de 2008. Ambas foram concedidas à Juliana de Oliveira Teixeira.

${ }^{12}$ De acordo com Silvandira de Almeira, Clairmont Orlando Gomes veio de Recife e chegou em Londrina no mesmo dia que começou a lecionar no Ginásio Londrinense. Sua passagem, porém, foi rápida, ficando apenas um ano - "talvez a família não tenha se adaptado", pontua Silvandira. 
(Holanda), em junho de 1907, ele foi o representante brasileiro, papel que "elevou-o à altura dos maiores países, conquistando glória para seu nome" (1944) e o codinome Águia de Haia. Por essa razão, o
GLERB resolveu adotar como símbolo uma águia (figura 1). Até hoje o colégio a mantém como símbolo, mas são poucos os que sabem que ela foi criação dos alunos pioneiros.

Figura 1. Logomarca do Grêmio Litero Esportivo Rui Barbosa

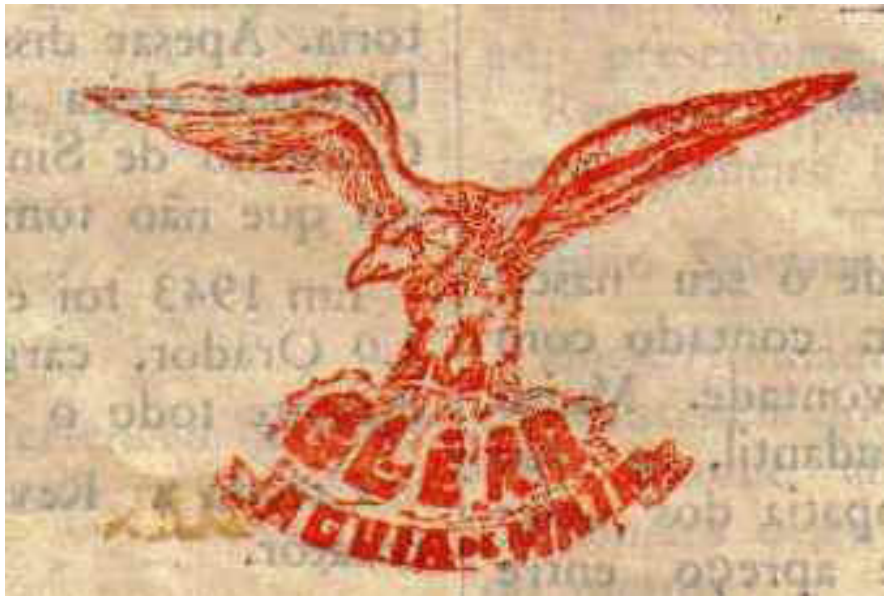

Fonte: Revista do Ginásio Londrinense (1944)

Como não há acesso a documentos (aliás, não se sabe se há documentos), é difícil montar uma trajetória evolutiva da organização do grêmio, sobretudo nos primeiros anos. Por isso, optamos por trazer a única formação da diretoria disponível, a de 1944, presente na Revista do Ginásio Londrinense números 7 e 8 (DIRETORIA..., 1944, p. 15-18).

Presidente: Pedro Faria Junior. Vice-presidente: Leda Maria Thereza Otranto, $1^{\circ}$. Secretário: Cláudio Damiano Stasiak. 2a Secretária: Paulina de Oliveira César. $1^{\circ}$. Orador: Izaurino Gomes Patriota. $2^{\circ}$. Orador: Manoel Barbosa de Souza. $1^{\circ}$. Tesoureiro: Iochial Kawahisa. $2^{\text {a }}$. Tesoureira: Dorothéa Passos. $1^{\circ}$. Bibliotecário: Milton Jensen. $2^{\circ}$. Bibliotecário: Albino Striquer. Diretor Esportivo: Alípio Brás. Diretora Esportiva: Circe Loures Bueno. Zelador: Cavalcanti de Almeida. Secretária da Revista: Leonor Camargo.

Todos os alunos podiam se aliar em grupos para concorrer às eleições anuais. A disputa entre as chapas "era um evento a parte", realizada com entusiasmo. Porém, Kilda Gimenez revela que já havia "um pessoal meio certo, que sempre acabava se elegendo. Dificilmente venciam os alunos que vinham transferidos, de fora".

Entre as atribuições do grêmio, pode-se estabelecer três frentes: esportiva, cívica e culturalliterária. Na parte esportiva, o GLERB era responsável pela organização de campeonatos que envolviam times de outros ginásios, como o Novo Atheneu, de Curitiba (PR), e Ginásio Cambará, de Cambará (PR), e times da própria cidade, como o da Casa Comercial Fuganti. As competições eram legalizadas por meio de um Alvará do Conselho Regional de Desportos do Paraná. Eram abertas ao público e divulgadas pela Rádio Londrina ${ }^{13}$. $\mathrm{O}$ esporte de mais destaque era o basquete, com um forte time masculino. Futebol e vôlei também eram praticados - este último, principalmente pelas meninas. Um fato interessante a se ressaltar é que o esporte feminino também era bastante ativo, sendo,

13 Rádio Londrina foi inaugurada em 15 de novembro de 1943. 
inclusive, reservado um cargo específico dentro da diretoria do grêmio, o de diretora esportiva.

No que diz respeito à parte cívica, o grêmio se encarregava de organizar desfiles em todas as datas comemorativas nacionais - reforçando o sentimento nacionalista que permeava a época devido a Segunda Guerra Mundial e a ditadura de Getúlio Vargas ${ }^{14}$. Segundo Paulina Silveira, o grêmio saía às ruas e a "participação dos alunos era total, já que todos eram sócios do GLERB”. Paulina recorda que também houve desfiles de caráter reivindicatórios, como o Desfile das Lanternas.

Lembro da vez que saímos às ruas à noite, com pequenas lanternas, cada um com uma. Nós estávamos protestando porque a energia elétrica de Londrina ainda era muito fraca, a iluminação pública era feita com pequenas lâmpadas, que nós chamávamos de 'tomatinhos'. Houve outra ocasião, também, que saímos em campanha pela cidade recolhendo pneus porque, com a guerra, a falta de borracha era muito grande. $\mathrm{E}$ conseguimos reunir muita coisa, o Ginásio foi o que mais arrecadou pneus!

A faceta cultural-literária, por fim, ganhará destaque neste trabalho. Desde a sua criação, o grêmio manteve reuniões semanais, todos os sábados a partir das $10 \mathrm{~h} 00$ para falar de literatura. De acordo com Kilda Gimenez, todos os alunos podiam participar, declamar poesias e cantar. Paulina Silveira complementa, dizendo que após as apresentações, sempre havia a crítica de algum professor, "orientando o que poderia ser melhorado ou elogiando o que tinha sido bom". Além disso, havia uma grande preocupação do GLERB em aumentar o acervo da biblioteca do ginásio - tanto que, na formação da sua diretoria, havia o cargo de bibliotecário. Campanhas para arrecadação de livros eram constantes e, inclusive, divulgadas pela revista:

[...] Devemos estudar para progredir e para progredir precisamos ler. Por isso, caros colegas, será necessário auxiliarmos a nossa paupérrima biblioteca onde escasseiam os bons livros. Ajudemos, portanto a enriquecê-la, não esquecendo que faremos uma grande obra, porque senão a aproveitarmos, aproveitarão nossos irmãos que por esse ginásio hão de passar (REVISTA DO GINÁSIO LONDRINENSE, 1944, p. 17).

A Rádio Londrina, que já divulgava os eventos esportivos do GLERB, também apoiava sua característica cultural. Uma vez por semana às $18 \mathrm{~h}$, relembram as alunas pioneiras, o grêmio tinha o espaço de uma hora para desenvolver seu programa: "A Hora Cultural do GLERB". Devido a escassez de documentos e de gravações, não foi possível determinar em qual dia o programa ia ao ar e estabelecer que conteúdos ele abrangia. De acordo com Kilda Gimenez, a Hora Cultural contava, geralmente, com alguma palestra ou discurso sobre uma data comemorativa da semana, encenação de "novelinhas" e declamação de poesias. Os "alunos mais ligados" ao grêmio, como Pedro Faria Junior e Izaurino Gomes Patriota, organizavam o programa, a participação, porém, era aberta a todos os associados. Frequentemente convidavam professores ou pessoas de destaque da cidade para falar a respeito de algum assunto ou data específica. Kilda Gimenez também conta que, das vezes que participou da Hora Cultural, "o locutor parecia que fazia questão de ficar na cara da gente! E você lia, falava e ele lá, bem no seu nariz! Mas eu ficava tão nervosa, me dava tanta raiva!" - brinca.

Partindo para o objeto de estudo principal desse artigo, o meio impresso, a iniciativa de se criar uma revista partiu do Prof. Clairmont Orlando Gomes.

Dr. Clairmont sempre teve em mente criar um órgão que fosse a voz do ginasiano [...]. Assim sendo, encontramos na Ata da I reunião da Diretoria do Grêmio Litero Esportivo Rui Barbosa, datada de 4 de dezembro de 1941, o seguinte trecho documentário: 'Ficou também

\footnotetext{
${ }^{14}$ A Segunda Guerra Mundial começou em 1939 e terminou em 1945; a ditadura de Getúlio Vargas teve início em 1937, com o estado Novo, e durou até outubro de 1945, quando ele foi deposto.
} 
resolvido que o nosso Grêmio publicará um jornal em principio de janeiro em comemoração ao Ano Novo, contando os principais fatos, atividades do mesmo, e trabalho dos alunos, etc; cujo nome escolhido foi ' $O$ Ginasiano'. Infelizmente não saiu a lume, 'O Ginasiano'. A razão não pudemos apurar, pois nada reza sobre este caso as atas seguintes. Mas, o motivo de O GINASIANO não ter saído a lume deve ter sido a partida repentina do Dr. Clairmont [...]. ( 1944, p. 8).

Assim, considerando as funções que a revista tinha que cumprir, foram analisados sua estrutura e conteúdo. Também foi analisado o nível de importância desse meio de comunicação dos alunos numa época conturbada pela guerra e pelo autoritarismo.

\section{Revista do Ginásio Londrinense}

O acervo disponível das Revistas do Ginásio Londrinense é bastante escasso. Só foi possível encontrar alguns números no acervo pessoal da aluna pioneira Kilda Gimenez. Além dessas três edições (figuras 2, 3 e 4), foi consultada, também, a Revista comemorativa do jubileu de formatura dos pioneiros do ensino secundário de Londrina, publicada em 1994, que traz artigos dos alunos da "turma pioneira" (1944), e reproduz a mesma capa utilizada na primeira edição da Revista do Ginásio Londrinense. Essa publicação é mais fácil de ser encontrada. Consta, inclusive, do acervo da Biblioteca Pública Municipal de Londrina.

A primeira revista do grêmio foi impressa em junho de 1943. Os números 2, 3 e 4 não foram encontrados para consulta, por isso, não há como estabelecer suas respectivas datas. Quanto ao período de duração da publicação da revista, não foi possível determinar quantos são os números posteriores à revista 7 e 8 , sabe-se, porém, que em 1946 ela ainda existia - fato que pode ser constatado pela reimpressão de um artigo na publicação comemorativa do jubileu de formatura (JUBILEU...,1994, p. 20): “Kilda Prado Gimenez escreveu o artigo acima quando cursava o $1^{\circ}$. Ano de Contabilidade e o publicou na 'REVISTA DO GINÁSIO LONDRINENSE’ de julho de 1946”.

Figura 2. Reprodução de capas da Revista do Ginásio Londrinense números: 5, de março de 1944

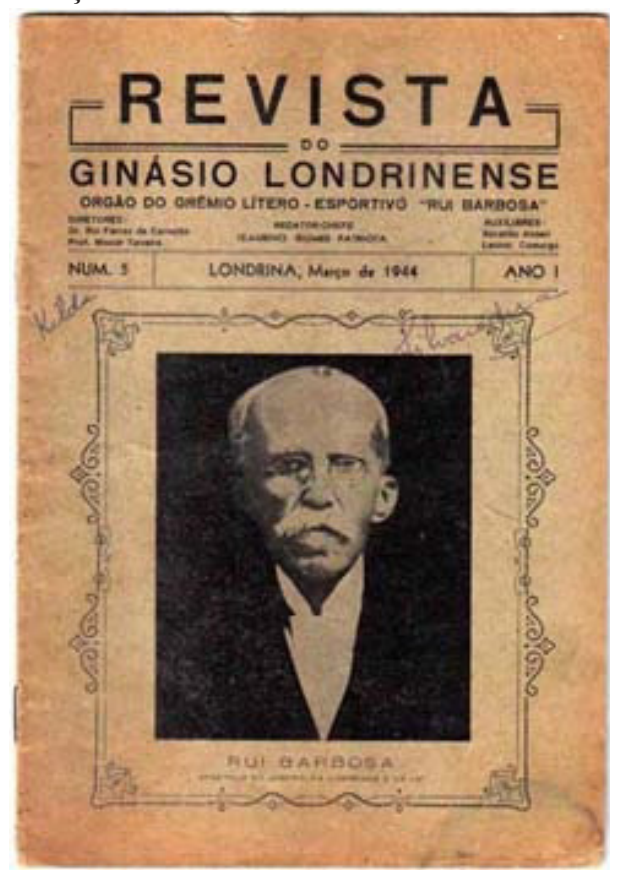

Fonte: Acervo pessoal da Sra. Kilda Gimenez 
Figura 3. Reprodução de capas da Revista do Ginásio Londrinense números 6, de abril de 1944.

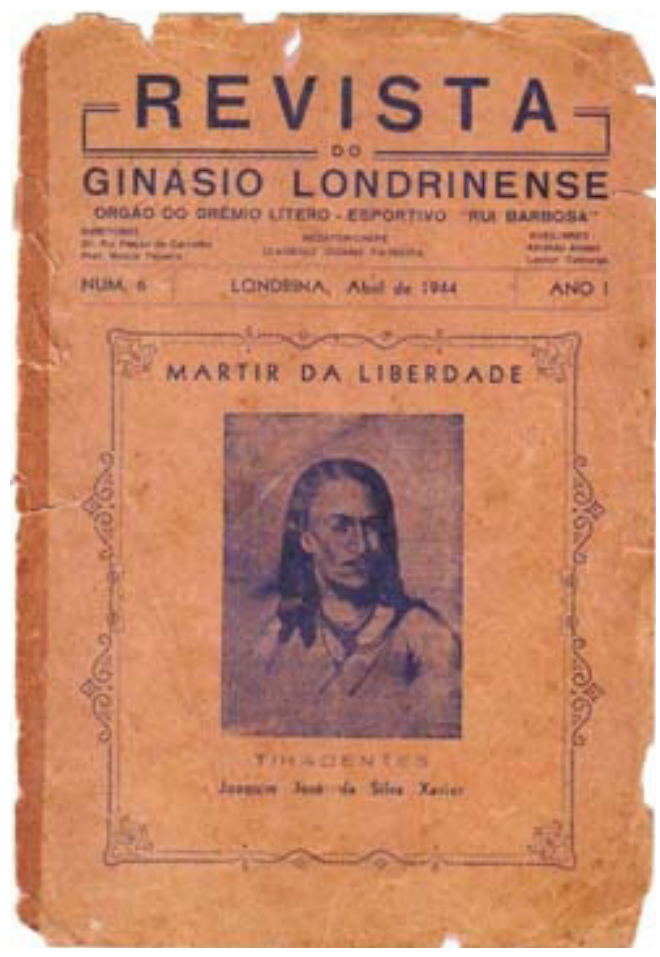

Fonte: Acervo pessoal da Sra. Kilda Gimenez

Figura 4. Reprodução de capas da Revista do Ginásio Londrinense números 7 e 8 de maio e junho de 1944.

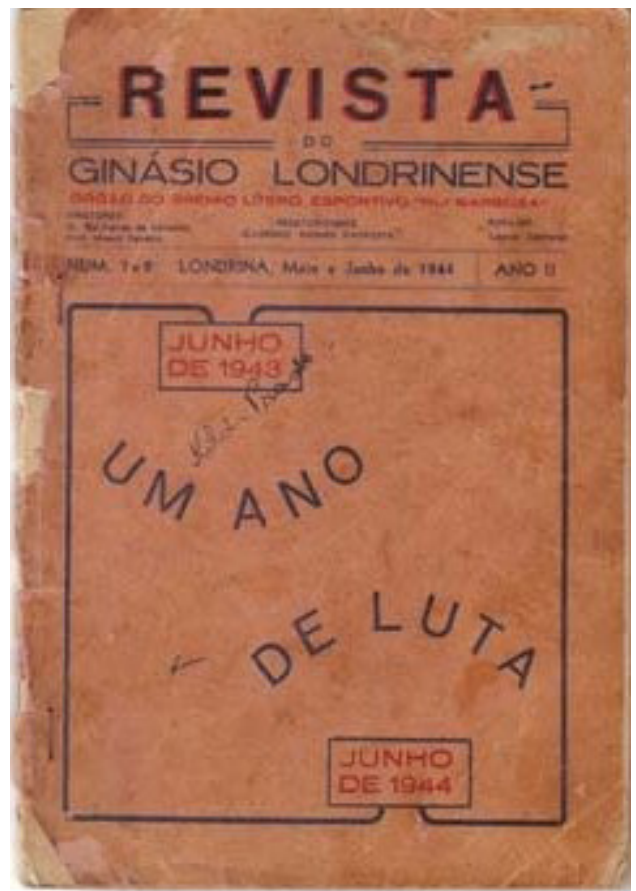

Fonte: Acervo pessoal da Sra. Kilda Gimenez 


\section{Características da Revista}

A Revista do Ginásio Londrinense tinha um formato semelhante a um gibi. As edições contavam com um número padrão de 20 páginas, que dobravam quando eram publicados dois números de uma só vez. O conteúdo era inteiro organizado pelo grêmio e a composição e impressão eram feitas pela Tipográfica Oliveira. Não há dados com relação à tiragem. Não existia qualquer tipo de publicidade na revista, posto que a mesma era custeada pelos próprios alunos, por meio de assinaturas, como é possível verificar em texto da edição de 1944:

As assinaturas dessa revista deverão ser solicitadas ao Sr. Mario Nishioka e seus auxiliares. Para as assinaturas de outra cidade, enviar a devida quantia $(\$ 20,00)$ pelo correio à Redação da Revista do Ginásio Londrinense, com endereço e nome legível. Aos alunos do Ginásio e sócios do GLERB é de obrigação assinar a revista.

Apesar da menção às assinaturas de outras cidades, as alunas pioneiras afirmam que nunca souberam de alguém de outro município que a tivesse assinado, sendo a circulação mais intensa entre os alunos do próprio ginásio. Como todos eram sócios do GLERB, todos podiam ter seus textos publicados. Cabia, então, ao editorchefe, Izaurino Gomes Patriota (eleito para o cargo durante os quatro anos em que cursou o ginasial) organizar o conteúdo, levar os materiais à tipografia, acompanhar a composição dos gráficos e a impressão da revista.

Comparando os quatro números disponibilizados para este trabalho (não se sabe se alguém tem a coleção completa da revista, mas as alunas pioneiras acreditam que ela não exista), é possível notar que as edições são bastante heterogêneas e, por trazerem textos de diversos assuntos e autores, não têm uma estrutura fixa. Porém, por meio da linguagem utilizada, a revista convergia para uma espécie de "identidade", uma linha editorial norteadora. Ela sempre abordava pontos-chave como o nacionalismo, a guerra, o humor e a poesia. Algumas seções também se repetiam nas edições, dando coesão aos números.

As seções mais observadas no universo pesquisado eram a Disse - que disse, reservada para o humor, com formato pequeno (ocupava menos da metade de uma página) e com diálogos entre dois ginasianos fictícios conversando sobre a escola ou sobre a própria revista; a Página Documentária (figura 5), que sempre reproduzia uma carta de Rui Barbosa para seu primo Albino José Barbosa de Oliveira; Versos e... Poetas $^{15}$ (figura 6), para versos e poesias de renomados poetas e, por fim, a seção Textos de Rui Barbosa (figura 7), sempre na página espelho (páginas 10 e 11), que, segundo a própria revista (PÁGINA..., 1944 , p. 25, "era esse um dos pontos capitais do programa a ser obedecido ao encetarmos as edições".

\footnotetext{
${ }^{15}$ Além dessa seção fixa, as revistas pesquisadas traziam poesias em outras páginas, de autoria tanto de autores consagrados como dos próprios alunos.
} 
Figura 5. Reproduções da Página Documentária, que tinha, inclusive, uma página fixa, a número 9. Seu conteúdo era sempre uma carta de Rui Barbosa a seu primo Albino de Oliveira.

A

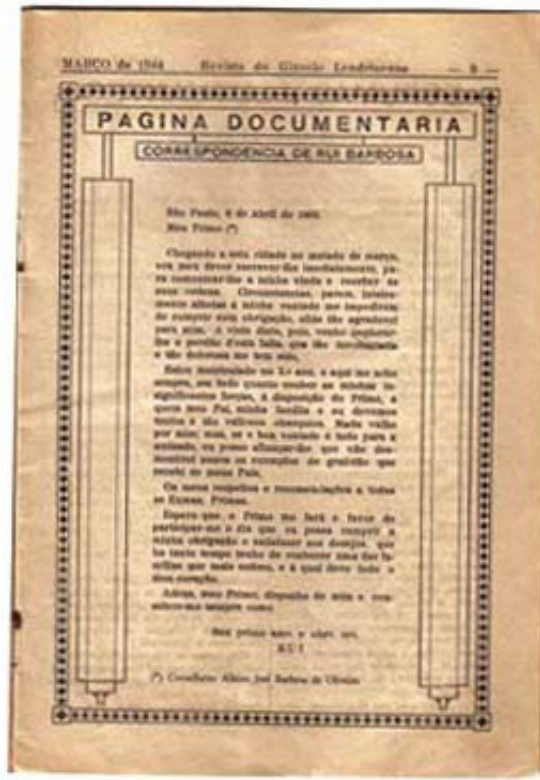

B

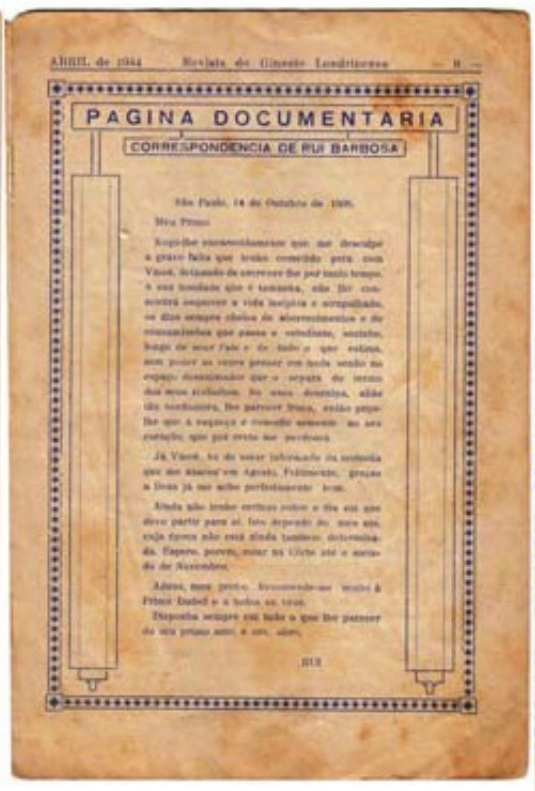

$\mathrm{C}$

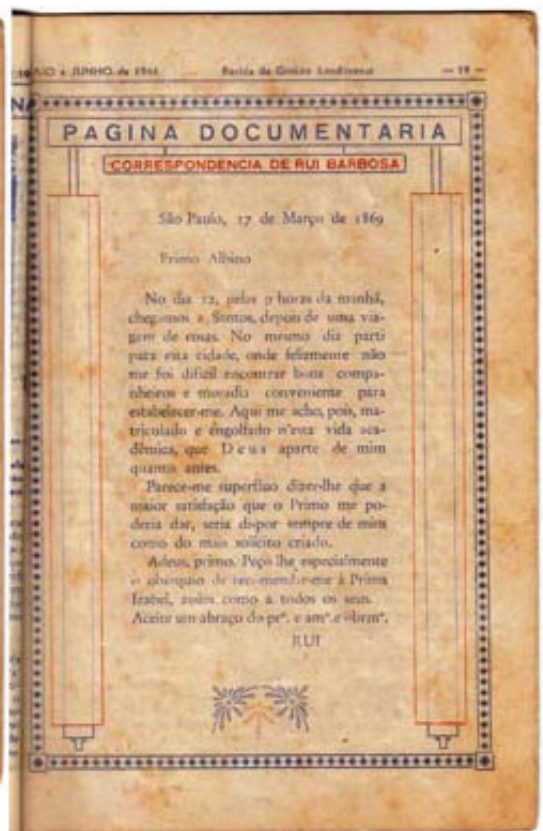

Fonte: Acervo pessoal da Sra. Kilda Gimenez

Figura 6. Reproduções da seção Versos e... Poetas, que também tinha página fixa, a número 12. O conteúdo era sempre uma poesia de algum autor renomado, como Olavo Bilac ou Castro Alves.

A

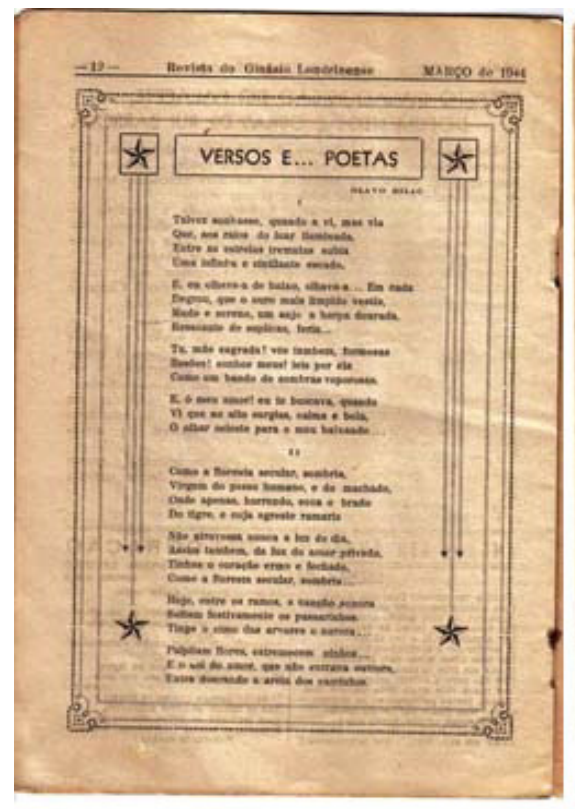

$\mathrm{B}$

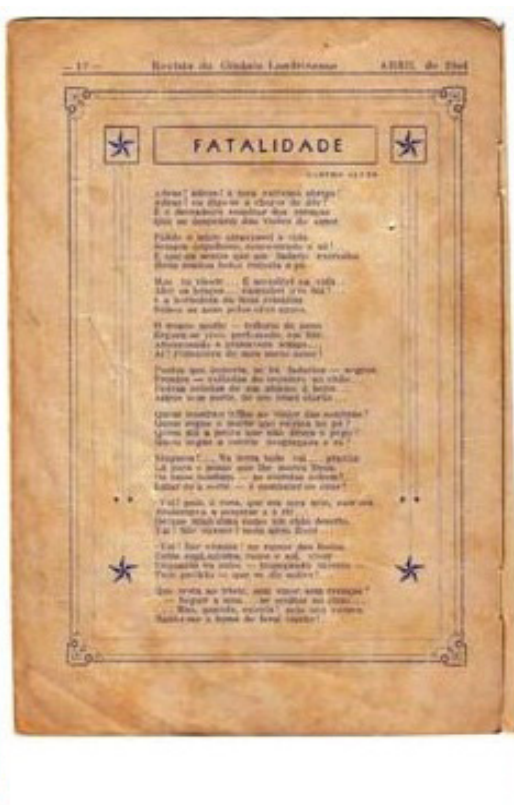

$\mathrm{C}$

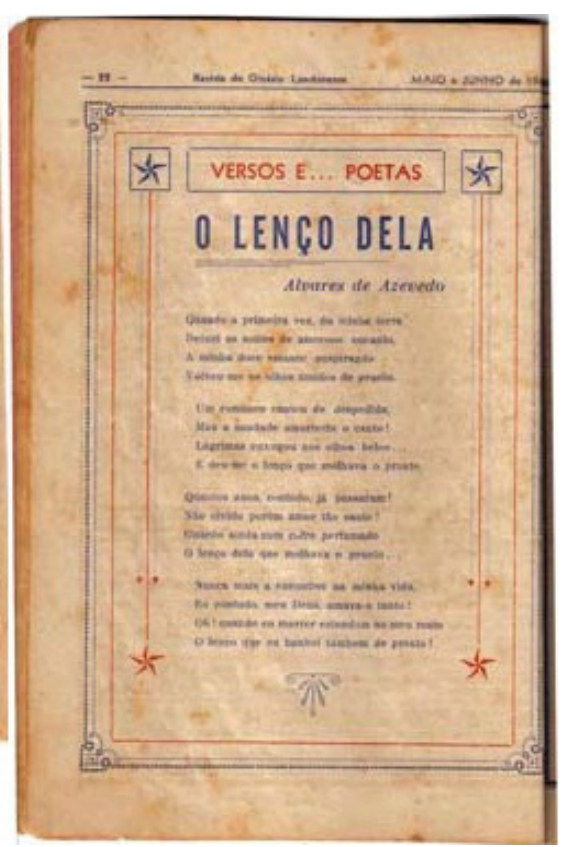

Fonte: Acervo pessoal da Sra. Kilda Gimenez 
Figura 7. Reproduções da seção Textos de Rui Barbosa, que ocupava a página espelho (páginas centrais) da revista: "um dos pontos capitais do programa".

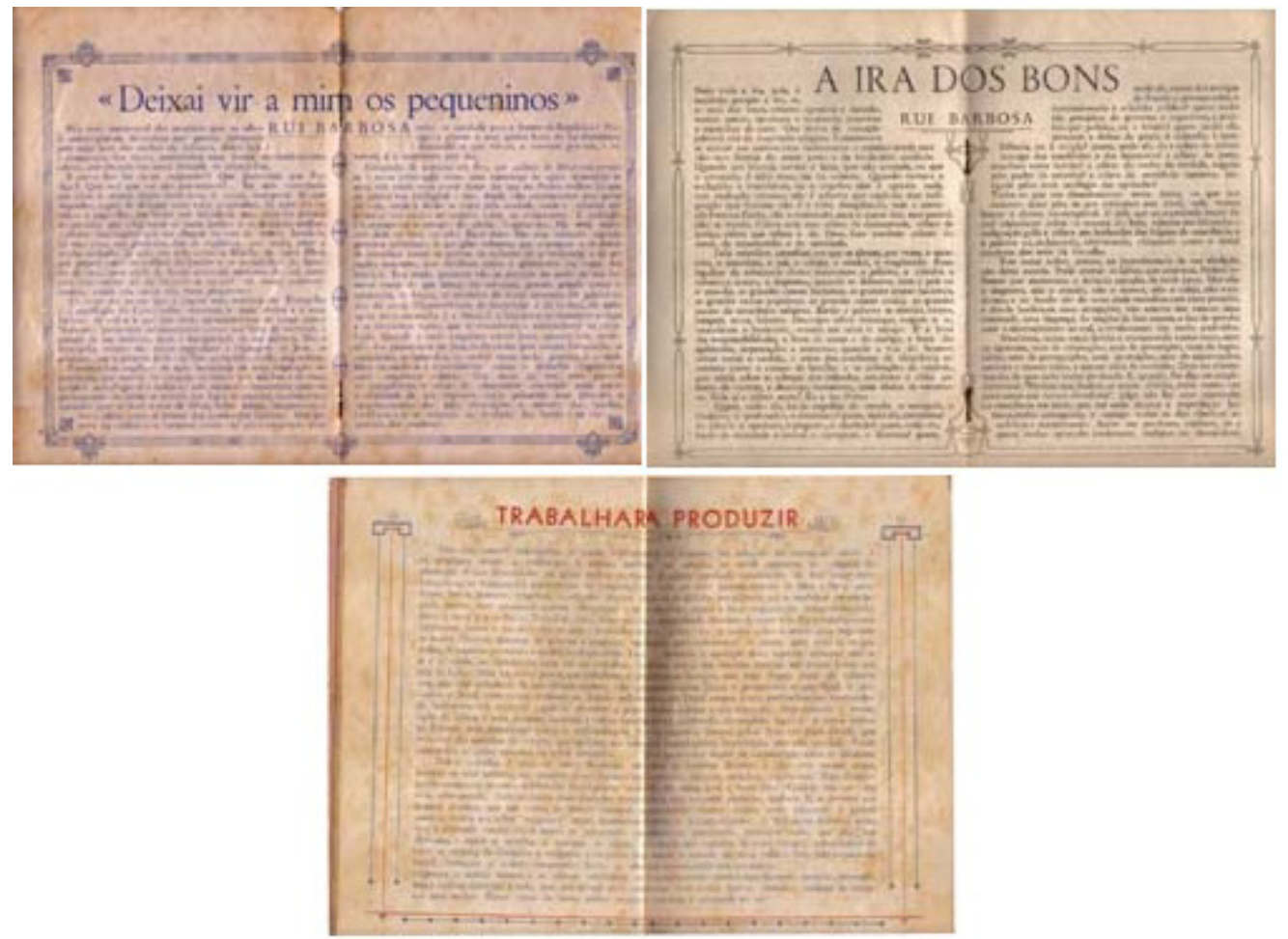

Fonte: Acervo pessoal da Sra. Kilda Gimenez

Além das seções fixas, característica ainda peculiar à impressa, a Revista do Ginásio Londrinense apresentava mais traços semelhantes às publicações atuais. Apesar de não serem tratados como editoriais, as quatro edições consultadas traziam textos que remetiam à capa, explicando a razão da sua escolha. Na revista número 5 (ano I, p. 14, março, 1944), por exemplo, há um texto somente sobre a capa e a sua imagem: "'[...] Comemorando essa data, estampamos o 'clichê' de Rui Barbosa em nossa capa, tendo por dístico o lema: Apóstolo do direito, Da liberdade e da Lei. Em um dístico jamais se poderia encerrar mais significação que o possua este".

Outro ponto interessante presente na revista de número 7 e 8 é uma coluna destinada à erratas (ano II, p. 35, maio e junho, 1944). Assim como nos impressos de hoje, a redação trouxe uma retratação aos excessivos erros de revisão do número anterior:

\begin{abstract}
Amigo leitor, já deveis ter notado ao ler o número de abril, a quantidade de erros de revisão. Vimos agora, justificarmos, de tão grande falta. O nosso intento era dar uma relação completa dos lapsos de revisão, mas não fazemos isto pois pouco ou nada adiantaria, seria uma leitura fastidiosa que haveríamos de apresentar. Fique pois como está. Desculpem-nos os caros leitores, e queiram aceitar a nossa justificativa.
\end{abstract}

\section{Análise de Conteúdo}

A "coesão" da revista pôde ser verificada pela linguagem, humor, nacionalismo, guerra e poesia. A análise de conteúdo das edições disponíveis permite traçar as características principais de cada um desses pontos. A linguagem, primeiramente, surge com uma verdadeira unidade. Apesar dos textos serem escritos por pessoas diferentes, a forma de expressar-se e a construção dos períodos é muito semelhante. Além disso, há uma preocupação 
poética que, mais do que se apresentar em versos, mostra-se também nas narrativas. Tomemos como exemplo um texto de Izaurino Gomes Patriota, sobre o primeiro aniversário da revista:

O SEU PRIMEIRO NÚMERO - uma avezita pousada no frouxel de nosso entusiasmo, enamorada do azul, mas ainda receosa de deferir os seus primeiros vôos [...]. HOJE - uma ave que, destemerosa, alça audaciosos vôos no inatingível azul dos nossos ideais juvenis [...]. AMANHÃ a avezita implume poderá metamorfosear-se em águia, enchendo o céu da Pátria com o rumor de seus remigíos [...]. (PATRIOTA, 1944, p. 3).

No que diz respeito ao humor, as edições contavam com a seção Disse - que disse que, além de ironizar fatos do cotidiano do próprio colégio, brincava com os professores. Esse é um ponto que merece destaque, pois, se havia essa liberdade, deveria haver um bom relacionamento entre os alunos e os docentes. Kilda Gimenez conta que cada turma tinha seu próprio padrinho, um professor escolhido por eles. Além disso, também relembra que havia "um carinho muito grande pelos mestres, alguns deles chegavam até a serem nossos amigos". Para ela, um dos professores mais queridos pelos alunos pioneiros era Vitorino Gonçalves Dias, professor de educação física. Em um dos textos da Disse - que disse..., Vitorino é colocado no meio da brincadeira:

Rebentacerca - [...] pois saiba dessa, a Sala da Biblioteca, a tradicional sala que também iria ser Redação da Revista agora é ponto...

Engoleposte - Mas ponto do que, homem de Deus? Ponto de bonde?

Rebentacerca - Eu vou lhe dizer. É... ponto dos... professores. [...] E não fica só nisso dizem por aí que também vai ser Delegacia. Delegacia e xadrez para quem roncar grosso. [...] Dizem que o Delegado vai ser o Prof. Vitorino... (DISSE..., 1944, p.16).

As questões do nacionalismo e da guerra são as mais interessantes das analisadas. Como o momento histórico era de Segunda Guerra Mundial e de ditadura no Brasil, a Revista do Ginásio Londrinense acabou se tornando uma rica fonte para se compreender a visão dos alunos e de como o ambiente da época influenciava suas idéias e opiniões. Para tanto, foram separados alguns trechos dos números consultados e o que se pôde observar é que os assuntos guerra, amor à pátria e exaltação da figura de Getúlio Vargas aparecem em todos eles. Na edição número 5 (MEDEIROS, 1944, p. 4), em um artigo solicitado pela própria revista, Orestes Medeiros (provavelmente uma pessoa de realce em Londrina) escreveu "Ascultai o âmago de tudo, procurando agir com firmeza para que os passos que vocês [jovens] deixem, não venham desservir o Brasil. É ascultando os gemidos da nossa terra, que fundiremos o aço rijo da nacionalidade."

$\mathrm{Na}$ edição número 6, que tem como capa uma imagem de Joaquim José da Silva Xavier, o Tiradentes, o texto Getúlio Vargas da aluna Carmem Xavier, não só exalta a figura do presidente, como a compara com a do herói:

Lá foi que um dia Getulio Vargas vendo o desencadear convulso da nossa pátria, afogada pela ambição e pelo desinteresse dos dirigentes, organizou uma nova conjuntura, tal qual Tiradentes organizara um dia, a conjuntura fracassada. Porém Getulio Vargas não fracassou: venceu o ânimo dos amigos e a bravura dos inimigos, como vencera em menino através dos campos, o animal indomável, senhor da campina. (XAVIER, 1944, p. 8).

Esta edição também traz o texto Minha Terra, da aluna Clarisse Ramos (1944, p. 18), no qual novamente o presidente é exaltado: "hoje nosso Presidente é considerado como o homem de maior glória em todo o território brasileiro [...]”. Essas demonstrações de respeito e, acima de tudo, de amor à figura do presidente permitem duas conclusões: ou a revista tinha algum tipo de censor que, além de fiscalizar, exigia que se escrevesse algo nesses termos; ou esse era realmente o sentimento da juventude da época. Silvandira de Almeida não se 
recorda se havia alguma espécie de censura dentro da revista, nem se os professores exerciam revisão de conteúdo. "Eu sei que eles liam nossa revistinha, que gostavam, mas acho que nem chegavam a passar por eles antes de ir para a tipografia. Quem cuidava da organização e revisão eram sempre o Pedro e o Izaurino".

Paulina Silveira, no texto Do Cafezal ao Perobal... Uma história a ser contada, publicado na revista do jubileu da formatura, em 1994, descreve "os tempos do nacionalismo exaltado", o que leva a concluir, de maneira geral, que esse era realmente o sentimento da época e não uma imposição.

Época de guerra para o mundo, de ditadura para o Brasil... Reinava um acendrado sentimento de civismo entre os jovens e, cada um, era um soldado em potencial, pronto para dar a própria vida pela defesa da Pátria se ela assim o exigisse. No Ginásio os estudantes se inflamavam de patriotismo. [...] O culto à Pátria era sagrado (SILVEIRA, 1994, p. 35, 1994).

Além de "impulsionar" o amor à pátria juntamente com o governo ditatorial, a Segunda Guerra Mundial era o principal assunto pautado pelos jovens do GLERB. Os temas abordados eram diversos: partida dos soldados, pedidos de paz, análises de caráter e o mais interessante - a guerra se infiltrava até nas piadas. A veia humorística, um dos pilares da revista já apresentados, unia-se às batalhas por meio de paródias, como a publicada na edição número 6. O texto de título "Em Guerra - Telegramas de Última Hora" é composto por pequenos telegramas do repórter "Desmiolado", correspondente do jornal "Folha Chifruda". Nomes como "comandante Bigode Roxo", "capital Pelanca", reforçam a descontração do enredo fundamentado em dois países em guerra, lutando bravamente com seus "estilingues" e "pelotas de barro”. (EM GUERRA..., 1944, p. 17-18)
Na revista de número 7 e 8 (ano II, p.25, maio e junho, 1944), a Segunda Guerra volta a ganhar bom humor numa pequena piada. O que merece destaque é que, sem a devida compreensão do momento histórico e das palavras "eixo" e "aliados"16, a graça, talvez, passe despercebida:

O professor repreende toda uma classe que demonstrava rebeldia em interpretar as suas ordens:

- Esta classe é a mais insubordinada que já conheci. Não se emenda por mais que se repreenda, se chame à ordem. Mas isso há de ter um fim. Hão de todos entrar no eixo...

- Engana-se professor. Entrar no eixo?... isto nunca e nunca. Nós somos aliados, e bem aliados, aliados da gema!

\section{Considerações Finais}

Depois de analisar as páginas dos poucos números disponíveis da Revista do Ginásio Londrinense e relacioná-las ao contexto histórico, foi possível observar que elas se erguem como uma riquíssima fonte histórica. A comunicação, enquanto processo fundamental de desenvolvimento social, acaba por refletir não só o que se pretende comunicar, mas também a própria época. Dessa forma, é essencial que se preservem os mais diversos tipos de comunicação - como as antigas "revistinhas" do tempo de escola - que, apesar de não terem projeção tão grande quanto de um jornal diário, podem ajudar na reconstrução do passado. Por meio deles, é possível abrir espaço para o resgate e preservação da história e, assim, compreender seu papel essencial na formação do presente.

\section{Agradecimentos}

Meus sinceros agradecimentos a todos aqueles que se disponibilizaram a ajudar esta pesquisa:

${ }^{16}$ Eixo era a maneira como os países da Alemanha, Itália e Japão foram denominados. Como eram inimigos diretos dos Aliados, grupo que o Brasil defendia juntamente com Estados Unidos, França, Inglaterra e União Soviética, entrar no "eixo" era inadmissível para os alunos. 
Célia e Ruth do Museu Histórico de Londrina, Lucinéia da Biblioteca Pública de Londrina e Irmã M. Paula Quessada e Elizabett Hatada do Colégio Mãe de Deus. Agradeço também às pioneiras que, sem dúvida, são a "alma" dessa história que procurei remontar: Kilda Gimenez, Paulina Silveira e Silvandira de Almeida. E, por fim, agradeço às companheiras de pesquisa Bruna Komarchesqui e Natália Rodrigues e ao orientador Prof. Dr. Paulo César Boni pelo apoio e amizade.

\section{Referências}

BERTAN, Tereza Canhadas. A educação confessional protestante: Instituto Filadélfia de Londrina 1944 a 1972. 1990. Tese (Doutorado em Educação) - Universidade Estadual de Campinas, Campinas.

BESPALHOK, Flávia Lúcia Bazan. A prática da reportagem radiofônica na emissora continental do Rio de Janeiro. 2006. Dissertação (Mestrado em Comunicação) - Faculdade de Arquitetura, Artes e Comunicação, UNESP, Bauru.

BOLETIM, MUSEU HISTÓRICO DE LONDRINA CARLOS WEISS. Londrina: Fundação Universidade Estadual de Londrina, n.1, jan./jul. 1980.

BONI, Paulo César. Fincando estacas! a história de Londrina (década de 30) em textos e imagens. Londrina: Do Autor, 2004.

BORGES, Vavy Pacheco. O que é história. 2. ed. São Paulo: Brasiliense, 2001.

CESAR, Zenite Teresinha Ribas. Estudo da evolução do ensino municipal de Londrina: 1930-1970. 1976. Tese (Livre Docência) - Universidade Federal do Paraná, Londrina.

DIRETORIA. Revista do Ginásio Londrinense, Londrina, ano 2, n.7-8, p.15-18, maio /jun. 1944).

DISSE - que disse. Revista do Ginásio Londrinense, Londrina, ano 1, n. 5, p. 16, mar. 1944. Sessão.

EM GUERRA: telegramas de última hora. Revista do Ginásio Londrinense, Londrina, ano 1, n. 6, p.17-18, abr. 1944

IBGE. Contagem da população em 2007. Disponível em: <http://www.ibge.gov.br/cidadesat/default. php.>. Acesso em: 17 jun. 2008.

JUBILEU de formatura dos pioneiros do ensino secundário de londrina. Revista Jubileu da formatura,
Londrina, n. 1, p. 20, 1994.

LAWAND, Dioneia. Colégio Mãe de Deus: aspectos históricos, filosóficos e pedagógicos da educação. 2002. Dissertação (Mestrado em Educação) - Universidade Estadual de Londrina, Londrina.

MEDEIROS, Orestes. Ascultai o âmago de tudo. Revista do Ginásio Londrinense, Londrina, ano 1, n. 5, p.4, mar. 1944.

MEIHY, José Carlos Sede Bom. Manual da história oral. 4. ed. São Paulo: Loyola, 2002.

PÁGINA documentária. Revista do Ginásio Londrinense, Londrina, ano 1, n. 5, p. 25, mar. 1944.

PATRIOTA, Izaurino Gomes. O seu primeiro número. Revista do Ginásio Londrinense, Londrina, ano 2, n.7- 8, p. 3, maio/ jun. 1944.

PELLEGRINI, Domingos. Revista 50 Anos de Arte. Londrina: Associação Médica de Londrina, 1991.

PERFIL do Dr. Clairmont Orlando Gomes. Revista do Ginásio Londrinense, Londrina, ano 2, n. 7-8, p. 5, maio/ jun. 1944.

RAMOS, Clarisse. Minha terra. Revista do Ginásio Londrinense, Londrina, ano 1, n. 6, p. 18, abr. 1944.

REVISTA DO GINÁSIO LONDRINENSE, Londrina, ano 1, n. 5, p. 2-20, maio/ jun. 1944.

RUI Barbosa. Revista do Ginásio Londrinense, Londrina, ano 2, n. 7-8, p. 12, maio/jun. 1944.

SILVEIRA, Paulina. Do cafezal ao perobal... uma história a ser contada. Revista Jubileu da Formatura, Londrina, n. 1, p. 35, 1994.

THOMPSON, Paul. A voz do passado: história oral. 3. ed. Rio de Janeiro: Paz e Terra, 2002.

XAVIER, Carmem. Getúlio Vargas. Revista do Ginásio Londrinense, Londrina, ano 1, n. 6, p. 8, abr. 1944.

Recebido em: janeiro 2010

Aceito em: abril 2010 
